\title{
Identification of manganese efficiency candidate genes in winter barley (Hordeum vulgare) using genome wide association mapping
}

\author{
Florian Leplat, Pai Rosager Pedas, Søren Kjærsgaard Rasmussen and Søren Husted
}

\begin{abstract}
Background: Manganese (Mn) has several essential functions in plants, including a role as cofactor in the oxygen evolving complex (OEC) of photosystem II (PSII). Manganese deficiency is a major plant nutritional disorder in winter cereals resulting in significant yield reductions and winter kill in more severe cases. Among the winter cereals, genotypes of winter barley are known to differ considerably in tolerance to Mn deficiency, but the genes controlling the Mn deficiency trait remains elusive.

Results: Experiments were conducted using 248 barley varieties, cultivated in six distinct environments prone to induce Mn deficiency. High-throughput phenotyping for Mn deficiency was performed by chlorophyll a (Chl a) fluorescence analysis to quantify the quantum yield efficiency of PSII. High-throughput phenotyping in combination with ICP-OES based multi-element analyses allowed detection of marker-trait associations by genome wide association (GWA) mapping. Several key candidate genes were identified, including PSII subunit proteins, germin like proteins and $\mathrm{Mn}$ superoxide dismutase. The putative roles of the encoded proteins in $\mathrm{Mn}$ dependent metabolic processes are discussed.

Conclusions: Fifty-four candidate genes were identified by Chl a fluorescence phenotyping and association genetics. Tolerance of plants to Mn deficiency, which is referred to as Mn efficiency, appeared to be a complex trait involving many genes. Moreover, the trait appeared to be highly dependent on the environmental conditions in field. This study provides the basis for an improved understanding of the parameters influencing Mn efficiency and is valuable in future plant breeding aiming at producing new varieties with improved tolerance to cultivation in soil prone to induce $\mathrm{Mn}$ deficiency.
\end{abstract}

Keywords: Chlorophyll (Chl) a fluorescence, Genome-wide association (GWA), Germin-like protein (GLP), Inductively coupled plasma - optical emission spectrometry (ICP-OES), Manganese (Mn) efficiency, Mn-SOD, Oxalate-oxidase (OxO), Photosystem II (PSII)

\section{Background}

Deficiency of the essential micronutrient manganese $(\mathrm{Mn})$ remains an unsolved problem that has a severe impact on crop production worldwide [1-4]. In addition to substantial yield losses, suboptimal use of nitrogen, phosphorus and water are marked side-effects of $\mathrm{Mn}$ deficiency. It is prevalent in areas with well aerated and

\footnotetext{
* Correspondence: shu@plen.ku.dk

Department of Plant and Environmental Sciences, University of Copenhagen, Thorvaldsensvej 40, 1871 Frederiksberg, Copenhagen, Denmark
}

high $\mathrm{pH}$ soils containing free carbonates and with high organic matter content [5]. Manganese deficiency often occurs as a latent disorder with no visual symptoms making it difficult to diagnose and follow up with timely Mn remediation [6]. Mn deficient plants have a decreased lignin content [7] and are therefore more prone to be infected by pathogens $[8,9]$ and have marked decreased winter hardiness $[6,10]$. Application of soluble Mn-fertilizers to the soil is an ineffective way to correct Mn-deficiency, as the added $\mathrm{Mn}$ is 
instantaneously made unavailable by oxidation to $\mathrm{MnO}_{2}$, due to soil chemical conditions [5]. Foliar applications of soluble manganous sulphate are more effective, but this is time consuming, expensive and often impractical for farmers cultivating marginal lands [11]. A second way for farmers to fight Mn deficiency induced yield losses is by deploying plant varieties with an improved tolerance to growth in soils with low Mn availability, defined as $\mathrm{Mn}$ efficient varieties $[3,12]$. Improving nutrient efficiencies by exploiting genetic diversity in plants and strategies to implement such traits into crop breeding have previously been suggested to improve plant productivity [13-16].

Previous studies on barley varieties have identified various phenotypes in terms of tolerance to low $\mathrm{Mn}$ availability in soil $[3,17]$, implying a genetic control of the trait. However, the genetic mechanisms involved in the ability of plants to cope with low amounts of plantavailable Mn have not yet been clarified. Several physiological mechanisms have been suggested to be involved in Mn efficiency in barley. For instance, it has been shown in barley that the Mn efficient variety Vanessa has a four-fold higher Mn uptake capacity compared with the Mn inefficient variety Antonia when exposed to sub-nanomolar Mn concentrations [18]. A follow-up study has suggested that this difference in uptake capacity is caused by different expression levels of the $\mathrm{Mn}$ transporter HvIRT1 [19]. However, Mn uptake and acropetal translocation involve many different transport pathways and their role in controlling $\mathrm{Mn}$ efficiency remains unknown [20]. It has also been proposed that chloroplasts are a main target for Mn deficiency and that $\mathrm{Mn}$ efficiency in barley is significantly influenced by processes linked to the stability and photochemical efficiency of the photosynthetic apparatus [21]. The photosynthetic apparatus seems more unstable when exposed to Mn limitations, with the amount of PsbA (D1) protein being reduced in the $\mathrm{Mn}$ inefficient variety Antonia compared to the Mn efficient variety Vanessa [22]. In addition, the ability to perform state transitions is only significantly decreased in the $\mathrm{Mn}$ inefficient varieties [21]. Furthermore, it has recently been suggested that exudation of enzymes to the rhizosphere (phytases dissolving organic chelated $\mathrm{Mn}$ ) is involved in the superior Mn efficiency of certain ancient barley landraces [23].

Manganese activates more than 35 enzymes in plant metabolism, including processes such as the activation of the enzyme phenylalanine ammonia-lyase (PAL) in the shikimic pathway [7], Golgi localized glycosyl transferases [24, 25], decarboxylases and dehydrogenases in the tricarboxylic acid cycle [5]. A few enzymes and processes have an irreplaceable requirement for $\mathrm{Mn}$ in plants: i) oxalate oxidase $(\mathrm{OxO})$ resulting in hydrogen peroxide production involved in pathogen attack [26]; ii) Mn superoxide dismutase (Mn-SOD) as a key enzyme involved in scavenging of reactive oxygen species in mitochondria and peroxisomes [27, 28]; iii) the oxidation of water (Hill-reaction) occurring in the oxygen-evolving complex (OEC) of photosystem II (PSII). Chl $a$ fluorescence measurements to diagnose Mn deficiency have proven to be a powerful research tool for measuring the severity of Mn deficiency and the impact of different Mn fertilizers [6, 10]. Chl a fluorescence is an in-vivo non-invasive and nondestructive technique enabling quantification of photosynthetic efficiency such as quantum yield efficiency of PSII $\left(\mathrm{F}_{\mathrm{V}} / \mathrm{F}_{\mathrm{M}}\right)$ [29]. This method can be extended to a high-throughput phenotyping method allowing for screening a large collection of cultivars.

In addition to phenotyping methods, the tremendous progresses made in genotyping major crop plants have enabled the search for QTLs and the identification of the underlying genes $[30,31]$. However, very little work has so far been undertaken on the genetic dissection of the quantitative traits controlling the adaptive response of crops to abiotic stress, including micronutrient deficiencies. QTL mapping and GWA have previously been shown to be promising methods to identify and characterize loci for nutrient efficiency [13, 32-35]. Initial genetic studies using yield improvements in response to Mn fertilization as a quantitative trait have suggested that Mn efficiency might be controlled by a single locus [36, 37]. Several RFLP markers have been identified on barley chromosome 4HS linked to the Mel1 locus for Mn efficiency. The role of Mel1 has been confirmed in field trials and glasshouse experiments and included in breeding programs in South Australia [38].

Barley is the fourth most important cereal crop in the world [39] and it is a widely geographically adapted and stress tolerant crop. In addition, co-localization of barley genetic loci within other cereal species (synteny) is available $[40,41]$, and the major progress achieved by sequencing the barley genome [42, 43] and its diploid nature, makes barley a versatile crop for genetic studies. Together with high-throughput genotyping single nucleotide polymorphism (SNP) platforms combined with fast phenotyping methods, GWA is a suitable tool to perform genetic studies of many traits and identified new genes.

The objectives of the current study were: to induce Mn deficiency in a collection of 248 European winter barley varieties cultivated under field and greenhouse conditions, to determine the variation in Mn efficiency by $\mathrm{Chl} a$ fluorescence and leaf tissue $\mathrm{Mn}$ concentrations by ICP-OES, and subsequently to carry out a GWA in order to provide a set of SNPs associated with the trait, followed by the identification of candidate genes involved in Mn efficiency. 


\section{Methods}

\section{Experimental design}

Plant material

The population consisted of 248 winter barley accessions (Hordeum Vulgare) collected across Europe (Additional file 1). The countries of origin most represented by the population were Denmark, France, Germany, Italy and the United Kingdom. A first set of 111 varieties came directly from the ExBarDiv collection (Genomics-assisted analysis and exploitation of barley diversity, ERA-PG funded project), with commercial cultivars released over the last 60 years. The collection was supplemented by 18 double-haploid lines from Sejet Plant Breeding (Denmark) and 27 varieties from CREA (Italy). Finally 92 varieties from European plant breeding companies were added. The population contained 139 two-row type and 109 six-row type varieties.

\section{Greenhouse experiment}

Plants were cultivated under greenhouse conditions in the autumn 2013. In order to induce Mn deficient conditions, soil was collected from Sweden $\left(55.58^{\circ} \mathrm{N}, 14.05^{\circ} \mathrm{E}\right.$, Skåne area) that is known to induce $\mathrm{Mn}$ deficiency in winter crops (unpublished data). Mn deficiency has been observed in uncompact and loose soil, therefore the soil was mixed with fine and coarse Leca ${ }^{\circ}$ (Light Expanded Clay Aggregate) and perlite. In terms of volume, the proportions were 45/25/15/15\% respectively of soil, perlite, fine Leca ${ }^{\oplus}(2-6 \mathrm{~mm})$ and coarse Leca ${ }^{\oplus}(6-10 \mathrm{~mm})$. Natural light was used and temperatures were maintained between 7 and $13{ }^{\circ} \mathrm{C}$. The whole collection was sown in $2 \mathrm{~L}$ pots containing three plants of the same variety. A randomized complete block design was used with four replicates of each variety. Pots were watered every two weeks directly from the bottom of the pots by capillarity for a period of $10 \mathrm{~min}$ before the water was removed.

\section{Field experiments}

Experiments were carried out in 2011, 2012 and 2013 (Table 1). In September 2011, one field previously known to induce severe $\mathrm{Mn}$ deficiency was sown in Sweden $\left(55.94^{\circ} \mathrm{N}, 14.19^{\circ} \mathrm{E}\right.$, Skåne area). In 2012 and
2013, two fields representing prevalent Danish sandy soil types were sown in Denmark (Saunte: $56.04^{\circ} \mathrm{N}, 12.30^{\circ} \mathrm{E}$; Lejre: $55.38^{\circ} \mathrm{N}, 11.57^{\circ} \mathrm{E}$; both sites at Sealand), where Mn deficiency had previously been observed. Field plots consisted of replicates of one meter long lines representing one variety. Replicated randomized designs were applied.

\section{Chl a fluorescence phenotyping}

Chl $a$ fluorescence was used to screen all experiments for Mn efficiency. Field and greenhouse fluorescence measurements were conducted using a handheld Plant Efficiency Analyser device (Handy PEA, Hansatech Instruments Limited, King's Lynn, UK). Due to seasonal variations and operational limitations, barley plants were measured at different plant development stages, from the three leaves stage to end of tillering (Table 1). Chl $a$ fluorescence is affected by chilling and freezing temperatures [44], thus screening was performed at temperature above $5{ }^{\circ} \mathrm{C}$. For each line in the field or pot in the greenhouse, three plants were measured using the youngest fully emerged leaves. After $25 \mathrm{~min}$ of dark-adaptation using Hansatech leaf clips, fluorescence measurements were recorded for $2 \mathrm{~s}$ after illumination with a saturating light pulse of $3000 \mu \mathrm{mol}$ photons $\mathrm{m}^{-2} \mathrm{~s}^{-1}$ on the adaxial leaf surface. Fluorescence transients (Fig. 1) and JIP-test parameters [45] were extracted using PEA Plus Software (v1.10). The JIP-test parameters used for the study are summarized (Table 2). The maximum quantum efficiency of PSII $\left(\mathrm{F}_{\mathrm{V}} / \mathrm{F}_{\mathrm{M}}\right)$ was used as the main stress indicator [46] as it has been demonstrated to be sensitive for Mn deficiency diagnosis [3, 6, 21]. However, Mn deficiency leads also to other marked changes in the transients [21]. Therefore, besides $F_{V} / F_{M}$, also the parameters $V_{I}, V_{J}, V_{K}$ and Area were analysed as the main parameters for association genetic analysis (Table 2). A full Mn-containing design as control was not realized. Indeed in regards to the PSII and the quantum yield efficiency parameter measured $\left(\mathrm{F}_{\mathrm{V}} / \mathrm{F}_{\mathrm{M}}\right)$, no diversity could be observed. Under those conditions, the quantum yield efficiency of PSII will reach its maximum with a value of $F_{V} / F_{M}$ around 0.82 . Instead of such Mn-containing design, control pots (or lines) were sprayed with a solution of manganese sulphate $\left(\mathrm{MnSO}_{4}\right)$

Table 1 Summary of the experiment framework used for Mn efficiency screening

\begin{tabular}{|c|c|c|c|c|c|c|c|c|}
\hline Environment & Sowing & $\begin{array}{l}\text { Screening } \\
\text { date }\end{array}$ & Abbreviation & $\begin{array}{l}\text { Population } \\
\text { size }\end{array}$ & $\begin{array}{l}\text { Number of } \\
\text { replicates }\end{array}$ & Growth stage & Phenotyping & $\begin{array}{l}\text { Number of } \\
\text { observations }\end{array}$ \\
\hline Kristianstad & Sep-11 & Nov-11 & KS11 & 112 & 10 & 5 leaves to beginning of tillering & Chl a & 3840 \\
\hline Lejre & Sep-12 & May-13 & LJ12 & 233 & 2 & End of tillering & $\mathrm{Chl} a$ & 1728 \\
\hline Saunte & Sep-12 & May-13 & ST12 & 233 & 2 & End of tillering & $\mathrm{Chl} a$ & 1512 \\
\hline Lejre & Sep-13 & Nov-13 & LJ13 & 248 & 3 & Beginning of tillering & $\mathrm{Chl} a$ & 2376 \\
\hline Greenhouse & Nov-13 & Dec-13 & $\mathrm{GH} 13 \mathrm{~A}$ & 248 & 2 & 3-4 leaves unfolded & $\begin{array}{l}\text { Chl a } \\
\text { ICP-OES }\end{array}$ & 1584 \\
\hline Greenhouse & Nov-13 & Jan-14 & $\mathrm{GH} 13 \mathrm{~B}$ & 248 & 2 & 5 leaves to beginning of tillering & $\mathrm{Chl} a$ & 1584 \\
\hline
\end{tabular}




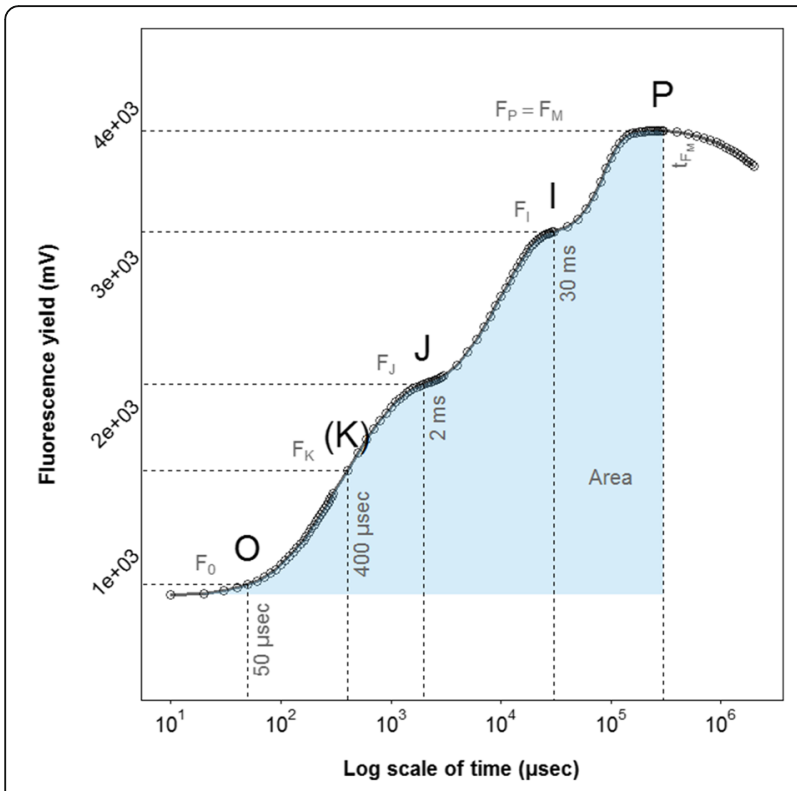

Fig. 1 A typical Chl a fluorescence transient from a barley plant grown at optimal conditions. The transient is plotted on a logarithmic time scale from $50 \mu \mathrm{s}$ to $1 \mathrm{~s}$. The features that give rise to the O-J-I-P designation are highlighted. The marks (dashed lines) refer to the selected fluorescence steps used for the calculation of structural and functional parameters. The signals are: the fluorescence intensity $F_{0}$ (at $50 \mu \mathrm{s}$ ), the fluorescence intensities $F_{j}$ (at $2 \mathrm{~ms}$ ) and $F_{I}$ (at $30 \mathrm{~ms}$ ) and the maximum fluorescence intensity $F_{P}=F_{M}\left(a t t F_{M}\right)$. The blue shade under the curve represents the area

at $0.1 \%$ of Mn containing two droplets of Tween 20 detergent per litre as described by Schmidt et al. [6], in the field and greenhouse experiments. Plants were measured two days after spraying.

\section{Mn concentration in leaf tissue}

In LJ13, only the controls samples were harvested and decontaminated following the method described by

Table 2 Quantifying PSII performance parameters obtained from the JIP-test based on the Chl a fluorescence transients

\begin{tabular}{|c|c|c|}
\hline \multicolumn{3}{|c|}{ Extracted and technical fluorescence parameters } \\
\hline $\mathrm{F}_{0}$ & $=$ & $\mathrm{F}_{50 \mu \mathrm{s},}$ fluorescence intensity at $50 \mu \mathrm{s}$ \\
\hline$F_{K}$ & $=$ & $\mathrm{F}_{400 \mu \mathrm{s}}$ fluorescence intensity at the $\mathrm{K}$ step (at $400 \mu \mathrm{s}$ ) \\
\hline$F_{\jmath}$ & $=$ & $\mathrm{F}_{2 \mathrm{~ms}}$ fluorescence intensity at the $\mathrm{J}$ step (at $2 \mathrm{~ms}$ ) \\
\hline$F_{1}$ & $=$ & $\mathrm{F}_{30 \mathrm{~ms}}$, fluorescence intensity at the I step (at $30 \mathrm{~ms}$ ) \\
\hline$F_{M}$ & $=$ & Maximum fluorescence intensity \\
\hline $\mathrm{F}_{\mathrm{V}}$ & $=$ & $\left(F_{M}-F_{0}\right)$, variable fluorescence from a dark adapted leaf \\
\hline$F_{V} / F_{M}$ & $=$ & Maximum quantum efficiency of PSII photochemistry. \\
\hline $\mathrm{tF}_{\mathrm{M}}$ & $=$ & Time to reach $F_{M}$, in $m s$ \\
\hline$V_{k}$ & $=$ & $\left(F_{K}-F_{0}\right) /\left(F_{M}-F_{0}\right)$, relative variable fluorescence at $400 \mu \mathrm{s}$ \\
\hline$V_{j}$ & $=$ & $\left(F_{J}-F_{0}\right) /\left(F_{M}-F_{0}\right)$, relative variable fluorescence at $2 \mathrm{~ms}$ \\
\hline$V_{1}$ & $=$ & $\left(F_{1}-F_{0}\right) /\left(F_{M}-F_{0}\right)$, relative variable fluorescence at $30 \mathrm{~ms}$ \\
\hline Area & $=$ & Area under the curve between $\mathrm{F}_{0}$ and $\mathrm{F}_{\mathrm{M}}$ \\
\hline
\end{tabular}

Schmidt et al. [6] in order to remove $\mathrm{MnSO}_{4}$ excess on the leaves surface. In GH13A, all the plants were sampled. The three youngest fully emerged leaves of each plant in the pots were harvested and bulked. For the digestion of samples, $15-30 \mathrm{mg}$ of freeze-dried leaves were mixed with $750 \mu \mathrm{L} 70 \% \mathrm{HNO}_{3}$ (SCP science, Quebec, Canada) and $375 \mu \mathrm{L} 15 \% \mathrm{H}_{2} \mathrm{O}_{2}$ (Sigma-Aldrich) and hereafter digested in a pressurised microwave oven (Ultrawave, Milestone Inc., Sorisole, Italy) for $10 \mathrm{~min}$ with a starting pressure of 40 bar and a temperature of $240{ }^{\circ} \mathrm{C}$. After digestion, samples were diluted to $14 \mathrm{~mL}$ with Milli-Q water (Milli-Q Plus, Bedford, Massachusetts, USA) before measurement on an ICP-OES (Model 5100, Agilent Technologies, California, USA) equipped with a Meinhard nebuliser and cyclonic spray chamber. For quantification, an external 10 point calibration standard $\mathrm{P} / \mathrm{N}$ 4400-132565 and 104 P/N 4400-ICP-MSCS (CPI International, Amsterdam, the Netherlands) was used. NIST 1515 Apple leaf certified reference material (National Institute of Standards and Technology, Gaithersburg, Maryland, USA) was analysed together with the samples to evaluate the accuracy and precision of the analysis. Data were accepted when the limit of quantification (LOQ) was exceeded and the accuracy was within $\pm 10 \%$ of the certified level and the coefficient of variation (CV\%) among replicates was below $5 \%$. Four technical replicates were made for all samples and seven for the reference material. The contents of 13 elements were determined and expressed in $\mu \mathrm{g} . \mathrm{g}^{-1}$ of leaf dry weight.

\section{Phenotypic analysis}

All phenotypic analyses were carried out using $\mathrm{R}$ version 3.1.0 [47]. To estimate the trait value across environments and replicates, estimates of the variance components were calculated using the general linear mixed model. Best linear unbiased predictors (BLUP) for each variety were calculated from a two-dimensional spatial mixed-model with measurement error using model from ASReml-R package $[48,49]$. BLUPs are reported as being suitable for plant breeding trials [50,51], moreover twodimensional spatial analysis allows taking into account variation in Mn efficiency amongst field and greenhouse experiments. BLUPs were calculated within environments using the formula:

$$
y_{i j}=z+g_{w(i)}+r_{w(j)}+v_{w(i j)}+e_{w(i j)}
$$

where $w_{0}$ indicates within environment, $y_{i j}$ is the response of the $i$-th variety for the $j$-th replicated-measurement, $z$ is the intercept, $g_{w(i)}$ is the $i$-th variety effect, $r_{w(j)}$ is the $j$-th replicated measurement effect, $v_{w(i j)}$ is the measurement error of the $i j$-th variety-replicated measurements. Finally, $e_{w(i j)}$ is the residual error which fits separable first order 
autoregressive two-dimensional spatial process to the variance structure of the line (or pot) errors. The intercept is taken as fixed effect whereas other terms are random effects.

Genetic determination of the trait $\left(\mathrm{H}^{2}\right)$ was calculated from the model according to the formula:

$$
H^{2}=\frac{\hat{\sigma}_{g}^{2}}{\hat{\sigma}_{g}^{2}+\hat{\sigma}_{r}^{2}+\hat{\sigma}_{v}^{2}+\hat{\sigma}_{e}^{2}}
$$

where $\hat{\sigma}_{g}^{2}$ is the genetic variance, $\hat{\sigma}_{r}^{2}$ is the variance of replicated measurements, $\hat{\sigma}_{v}^{2}$ is the variance of measurement error and $\hat{\sigma}_{e}^{2}$ is the residual variance.

\section{Genetic analyses}

\section{Collection genotyping}

The whole population of winter barley varieties was genotyped with SNP markers by TraitGenetics $\mathrm{GmbH}$ (Gatersleben, Germany). Samples were genotyped using the Illumina iSelect $9 \mathrm{k}$ barley Infinium chip [52]. Allele calling was performed at TraitGenetics using the company's own cluster file based on a diversity panel.

Intra-chromosomal positions used for the GWA were based on the physical map of barley [42] in order to locate the associated SNP on the genome. After pre-processing with minor allele frequencies (MAF) $<0.01$ and with a call rate $>0.75$, a final set of 5,706 SNPs was retained in the study, including 4,761 SNPs with known positions on the reference map [42].

\section{Population structure calculation}

The software package STRUCTURE [53] was used to infer the population structure. This approach uses multi-locus genotypic data to assign individuals to groups $(\mathrm{k})$ without prior knowledge of population genetic relationship under Hardy-Weinberg equilibrium assumption. The calculation was done using the ParallelStructure $R$ package [54]. STRUCTURE runs were distributed over 22 cores on a server to speed up the calculations. To determine the number of subpopulation (k), a first run was done, with a burn-in period of 25000 and 250000 Monte Carlo Markov Chain (MCMC) iterations, for $\mathrm{k}$ ranged from 1 to 10 with 15 independent replicates for each $k$. The admixture model with correlated allele frequencies was applied. The optimum number of subpopulation estimation was based on the ad hoc statistic $(\Delta \mathrm{K})[55]$ implemented in Structure Harvester website [56], based the ad hoc statistic $(\Delta \mathrm{K})$. The number of optimum subpopulation $\mathrm{k}$ was set to $\mathrm{k}=4$, therefore a new run was used to assign the genotypes to each subpopulation cluster with a setup with burn-in period of 100000, $500000 \mathrm{MCMC}$ and 40 replicates for the estimate $\mathrm{k}$. Results of independent runs for the same value of $\mathrm{k}$ were summarized using the CLUMPP software [57]. Estimation of membership coefficient was calculated with the Greedy permutation algorithm option with 100000 random input order repeats and plotted using Distruct software [58].

\section{GWA model}

The GAPIT $R$ package was used for GWA [59]. The final GWA was performed using a modified mixed linear model taking. It takes into account multiple levels of relatedness and population matrix as cofactor [60,61]. The pairwise relatedness matrix also called the genomic relationship or Kinship matrix was used to correct for relatedness in the GWA model and calculated using the Loiselle method [62]. Its dimension was ( $\mathrm{n} x \mathrm{n})$, where $\mathrm{n}$ is the number of individuals. The developed model follows:

$$
\boldsymbol{Y}=X \boldsymbol{\beta}+Q v+Z \boldsymbol{u}+\boldsymbol{e}
$$

where $Y$ is the phenotypic response vector, $X$ is the molecular marker matrix, $\boldsymbol{\beta}$ is the vector of fixed effect for the marker to be estimated, $Q$ is the posterior probabilities matrix belonging to each population obtained for $k=4, v$ is the vector of fixed effect for population structure, $Z$ is the Kinship matrix, $\boldsymbol{u}$ is the vector of random effect for co-ancestry, and $\boldsymbol{e}$ is the vector of residuals. Only SNP markers with a P-value $<0.001$ are presented in the results.

\section{Bioinformatics on candidate genes}

SNPs associated with the Chl $a$ fluorescence based parameters were blasted in the BARLEYMAP database [63]. The data-base refers to the barley physical map [42] and specify gene annotations upstream and downstream of the SNP in question. The blast window was extended to half the extent of linkage disequilibrium (LD) (Table 3) at both QTL region extremities, respectively and to each chromosome LD. In order to calculate LD extent, pairwise LD between loci was calculated in TASSEL version 5.0 [64] and the LD extent was implemented using the method described by Breseghello et al. [65].

Table 3 Intra-chromosomal extent of LD measured in the 248 winter barley collection

\begin{tabular}{lll}
\hline Chromosomes & Extent of LD (cM) & Number of SNPs \\
\hline $1 \mathrm{H}$ & 6.5 & 490 \\
$2 \mathrm{H}$ & 15.4 & 802 \\
$3 \mathrm{H}$ & 14.7 & 736 \\
$4 \mathrm{H}$ & 8.2 & 528 \\
$5 \mathrm{H}$ & 14.3 & 870 \\
$6 \mathrm{H}$ & 9.5 & 666 \\
$7 \mathrm{H}$ & 18.5 & 669 \\
\hline
\end{tabular}




\section{Results}

\section{Selection of environments}

Six different environments were used in the study to screen the 248 varieties of the winter barley collection. Mn deficiency induction cannot be easily controlled in fields and soil pots. Environmental effects such as temperature, soil humidity and redox states, all have major impacts on Mn plant availability and consequently on Mn deficiency development [66]. Consequently genotype-by-environment interactions were expected.

Therefore to study these interactions, genetic determination of the $\mathrm{F}_{\mathrm{V}} / \mathrm{F}_{\mathrm{M}}$ related trait, also called heritability $\left(\mathrm{H}^{2}\right)$, and genetic correlation were calculated (Table 4). $\mathrm{H}^{2}$ characterizes the variance of the trait captured by the genotypic effects relative to the total phenotypic variance. The two field sites ST12 and LJ12 showed very low $\mathrm{H}^{2}$, at 0.06 for both whereas $\mathrm{H}^{2}$ was up to 0.31 for the greenhouse experiment GH13A. The low $\mathrm{H}^{2}$ estimated show that only a minor fraction of the total variance is due to genetic effects. In addition, when looking at $\mathrm{F}_{\mathrm{V}} / \mathrm{F}_{\mathrm{M}}$ genotypic estimates in the 6 environments (Fig. 2), the response range to low $\mathrm{Mn}$ availability ranged from 0.38 to 0.71 in LJ13 whereas LJ12 had $F_{V} / F_{M}$ values from 0.72 to 0.76 and $S T 12$ from 0.66 to 0.74. Indeed LJ12 and ST12 were phenotype in spring whereas the other environments were screened in winter. The winter 2012/13 was too wet and mild to induce Mn deficiency, while it is induced mostly under dry and cold conditions. Consequently, because of low $\mathrm{H}^{2}$, narrow variability and inadequate phenotyping time, it was decided to discard ST12 and LJ12 from the GWA analysis.

Calculation of genetic correlations across environments (Table 4) provided a better understanding of how genetic control of Mn efficiency is related across the different environments. The weak genetic correlations confirmed that the Mn efficiency trait had differential genetic determination depending on environments also named genotype $x$ environment interactions. These contrasts across environments can be explained by several factors including climate (solar irradiation, soil humidity and temperature) and physiological age of the plants relative to the time of Chl a measurements. Indeed, the severity of Mn deficiency is subject to major fluctuations over time and consequently it was also expected that the genetic variability

Table 4 Genetic correlation between environments and genetic determination $\left(\mathrm{H}^{2}\right)$ estimated by model for the $\mathrm{F}_{\mathrm{V}} / \mathrm{F}_{\mathrm{M}}$ trait

\begin{tabular}{llllllll}
\hline Environments & GH13A & GH13B & KS11 & LJ12 & LJ13 & ST12 & $H^{2}$ \\
\hline GH13A & 1 & & & & & & 0.31 \\
GH13B & 0.61 & 1 & & & & & 0.26 \\
KS11 & -0.02 & -0.11 & 1 & & & & 0.18 \\
L12 & 0.14 & 0.16 & 0.71 & 1 & & & 0.06 \\
LJ13 & 0.27 & 0.28 & 0.16 & 0.25 & 1 & & 0.23 \\
ST12 & 0.11 & 0.14 & 0.24 & 0.84 & 0.2 & 1 & 0.06 \\
\hline
\end{tabular}

among the varieties would be affected. Moreover, the ranking of variety's $F_{V} / F_{M}$ performances fluctuated over the environments and no grouping of variety in regards to their origins or row-type was observed.

\section{Assessment of plant response to Mn deficiency}

To validate the induction of Mn deficiency, plants in soil pots and in fields were sprayed with soluble Mn and measured two days after spraying. In all four environments, a clear impact of $\mathrm{MnSO}_{4}$ foliar application was recorded on Chl $a$ fluorescence curves and $\mathrm{F}_{\mathrm{V}} / \mathrm{F}_{\mathrm{M}}$ values (Fig. 3). The fluorescence yield $F_{V} / F_{M}$ of plants treated rose to a higher level (between 0.75 and 0.83) whereas the control plants remained at lower levels (between 0.47 and 0.66) (Fig. 3 b), confirming that the plants were indeed Mn deficient, but without any visual leaf symptoms (latent Mn deficiency). Therefore the ability to fully restore $F_{V} / F_{M}$ to its maximum after foliar application of Mn sulfate confirmed that $\mathrm{Mn}$ is the only abiotic stress parameters influencing the $F_{V} / F_{M}$ values under the conditions prevailing at the field sites and in the green house experiment. The J and I steps of the transients were flattened and less defined, and in severe cases a notable K-step was developed (Fig. 3 a). The most severe Mn deficient conditions were seen in the GH13B experiment in which Mn deficient plants showed flat J and I slopes. Furthermore, when Mn deficient plants in $\mathrm{LJ} 13$ were sprayed with $\mathrm{MnSO}_{4}$, the Mn concentration in leaf tissues increased significantly (Fig. 3 c). Therefore, spraying of Mn salts confirmed that Mn deficiency was induced and that plants can fully recover the maximum range of $\mathrm{F}_{\mathrm{V}} / \mathrm{F}_{\mathrm{M}}$. Moreover, the ICP-OES quantification of other nutrients indicated that their concentration in leaf tissues remained stable (Additional file 2). Consequently only $\mathrm{Mn}$ was responsible for the change of $\mathrm{F}_{\mathrm{V}} / \mathrm{F}_{\mathrm{M}}$.

Mn leaf concentration ranged from around 7 to 11.5 $\mu \mathrm{gg}^{-1}$ of DW and the $\mathrm{H}^{2}$ of Mn concentration in leaf tissue was 0.33 . The Pearson correlation and its associated Pvalue showed the highest correlation between $\mathrm{F}_{\mathrm{V}} / \mathrm{F}_{\mathrm{M}}$ and $\mathrm{Mn}$ concentration at 0.59 . The correlations were much lower with the other fluorescence parameters (Table 5).

Based on the differences in $\mathrm{F}_{\mathrm{V}} / \mathrm{F}_{\mathrm{M}}$, on the shape of the curves and on Mn leaf tissue concentration, it was evident that plants were exposed to Mn deficiency.

\section{Grouping from the population structure}

The structuration analysis allowed us to distinguish four groups (Fig. 4). Two groups of two-rows from mid-northern Europe were identified. One group of sixrows and one group with a mixture of six-rows and two-rows from a southern European origin were also detected. In blue, the group with two-rows contained most of the breeding lines of Scandinavian origin. It confirmed the significance of adding population structure into the GWA model. 


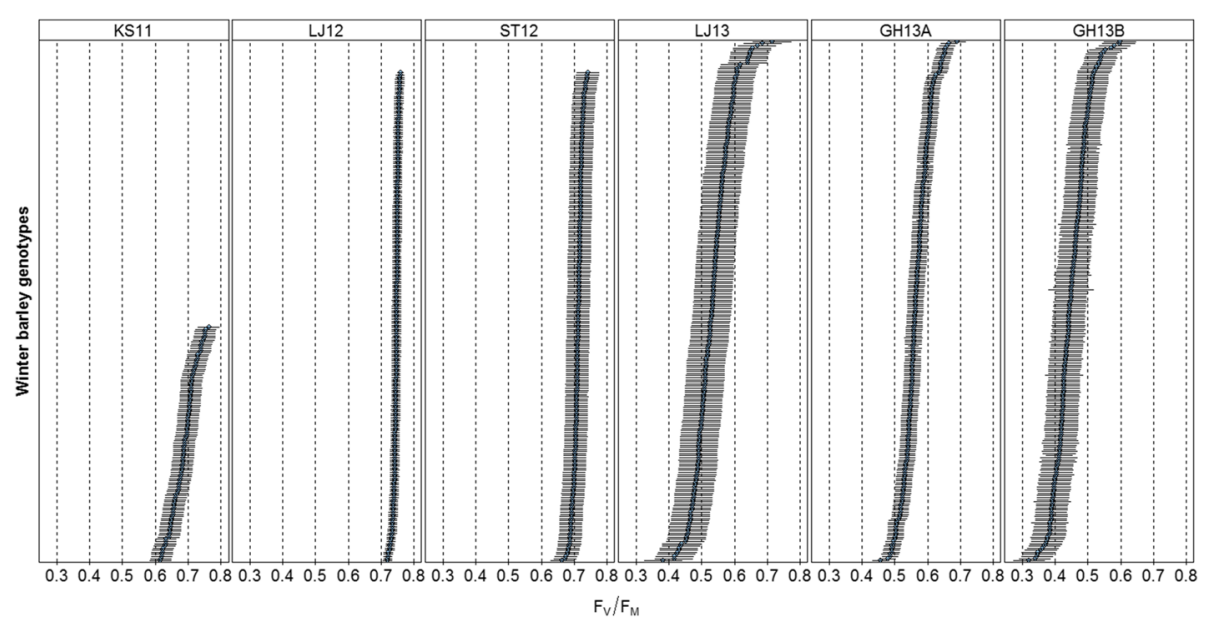

Fig. $2 \mathrm{~F} / \mathrm{F}_{\mathrm{M}}$ genotypic estimates presented by environments in the 248 winter barley population. Data represent the ranked BLUPs and their standard errors for each variety grown in Mn deficient soils

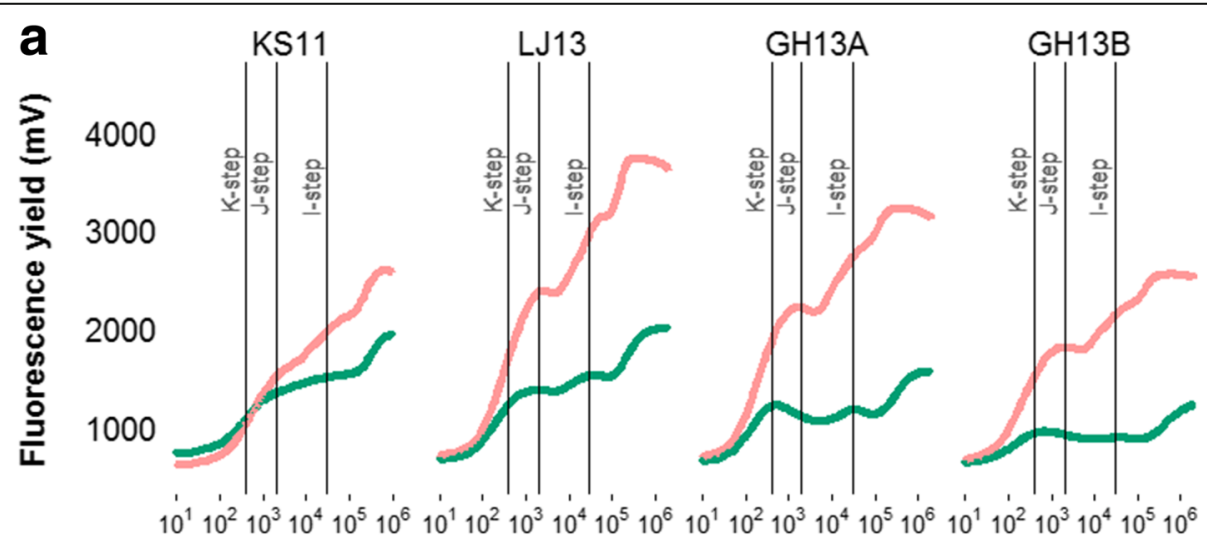

Log scale of time ( $\mu$ sec)
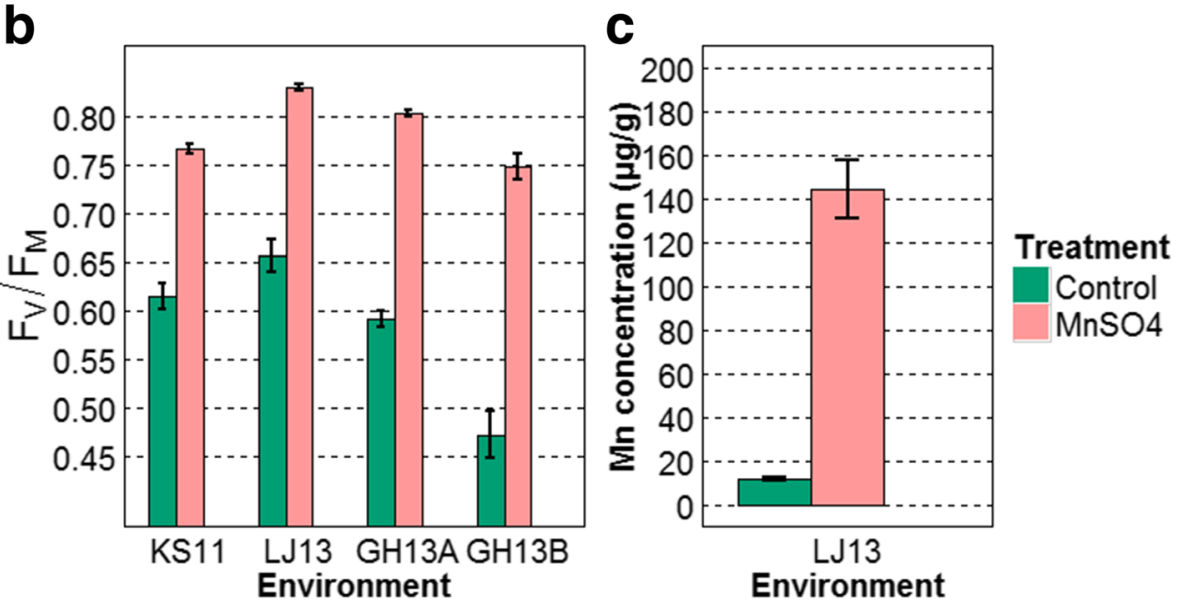

Fig. 3 a Chl a fluorescence OJIP curves presented by treatments and environments (mean of replicates $(24 \leq n \leq 45)$ ). $\mathbf{b}$ FV/ $F_{M}$ values results calculated from Chl a fluorescence curves under different spraying treatments, and standard error over replicates are plotted with error bar. Finally, the plot (c) shows the Mn concentration in $\mu \mathrm{g} \cdot \mathrm{g}^{-1}$ of DW leaf tissue. In green, barley plants as controls did not receive any treatment application; in red, plants were sprayed with $\mathrm{MnSO}_{4}$ solution 
Table 5 Correlations and the associated P-values of Mn concentration in leaf with $\mathrm{Chl}$ a fluorescence parameters

\begin{tabular}{lcl}
\hline Fluorescence parameters & Correlation & P-value \\
\hline$F_{\bigvee} / F_{M}$ & 0.59 & $<0.001$ \\
$V_{I}$ & 0.32 & $<0.001$ \\
$V_{J}$ & 0.03 & 0.659 \\
Area & 0.22 & $<0.001$ \\
$V_{K}$ & 0.37 & $<0.001$ \\
\hline
\end{tabular}

\section{GWA results}

Taken together for the four environments considered, 54 SNP markers were found to be significantly associated with the $F_{V} / F_{M}$ trait $(P$-value $<0.001)$ and were distributed over 6 chromosomes. Of these, 11 were unmapped SNPs with missing annotations. Marker-trait association displayed distinct peaks corresponding to QTLs (Fig. 5). Other associations were detected for all JIP parameters and are discussed below. Despite strong genotype $x$ environment interactions, a meta-analysis including all environments (data not shown) resulted in the identification of the same variants. However it does not reflect the reality as most of the associations are environment-specific. Different SNPs were detected in each environment (Fig. 5) implying that marker-trait associations are severely affected by the environment. In contrast, only four SNPs were identified using the Mn leaf concentrations (Additional file 3). Three markers constitute one peak on chromosome $6 \mathrm{H}$ and one marker on chromosome $5 \mathrm{H}$.

\section{Putative candidate genes}

Recent advance in barley genome sequencing [42] allows candidate genes to be sought for in the flanking region of the SNP associations. Furthermore, the iSelect array was designed with SNP markers located in the genic region of known genes [67]. Therefore, the significant SNPs for each of the peaks were blasted against databases [63] to identify candidate genes in the surrounding region of associations. Putative candidate genes controlling $\mathrm{Mn}$ efficiency and their positions on the genome were identified in the corresponding blasted genic region. Based on prior knowledge about physiological mechanisms involving $\mathrm{Mn}$, numerous genes coding for proteins have been reported and classified for $F_{V} / F_{M}$, Area, $V_{I}, V_{J}$ and $V_{K}$ fluorescence parameters (Table 6, Additional file 4). However, no putative genes have been reported for $\mathrm{Mn}$ leaf concentration data obtained by ICP-OES. It is suggested that all the candidate genes play a role in Mn dependent pathways and these are presented below.

\section{Photosystem II subunits}

Different Psb subunits from PSII were found at the exact position or close to the SNP associated with the trait by GWA. Of these, a highly significant association $\left(-\log _{10}\left(\mathrm{P}_{\mathrm{val}}\right)=3.7\right)$ was found for $\mathrm{F}_{\mathrm{V}} / \mathrm{F}_{\mathrm{M}}$ in $\mathrm{KS} 11$ with SNP 11_10254 located on 5H chromosome at $159.5 \mathrm{cM}$. Gene AK251925.1 was found at the same position coding for Psb28 PSII subunit. Other marker-associations pointed out genes coding for PSII subunits; AK249774.1 (54.3 cM on chromosome 4H), MLOC_77860.1 (124.6 cM on chromosome $7 \mathrm{H}$ ) coding for PsbP PSII subunit were also identified with a close co-localization of significant SNPs (Table 6). Besides these results, PsbW and PsbN $\left(\mathrm{F}_{\mathrm{V}} / \mathrm{F}_{\mathrm{M}}\right.$ trait) and PsbQ (Area trait) PSII subunits coding genes were also found significant markerassociations, however they remained always more distant to the closest SNP.
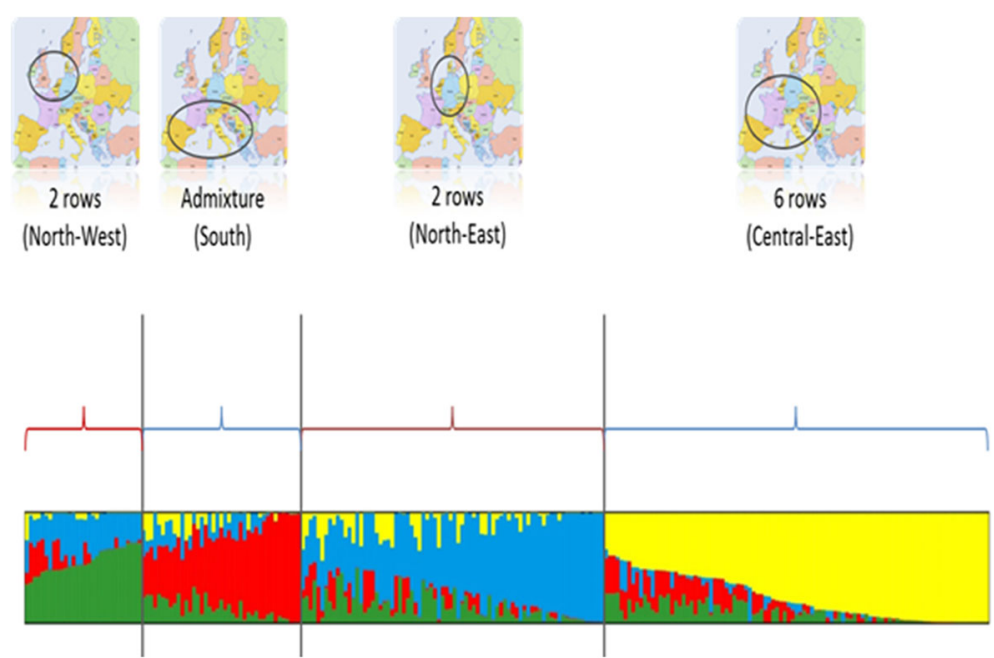

Fig. 4 Allocation proportions of each variety to the four subpopulations. Each bar represents one variety, and each colour, one subpopulation 


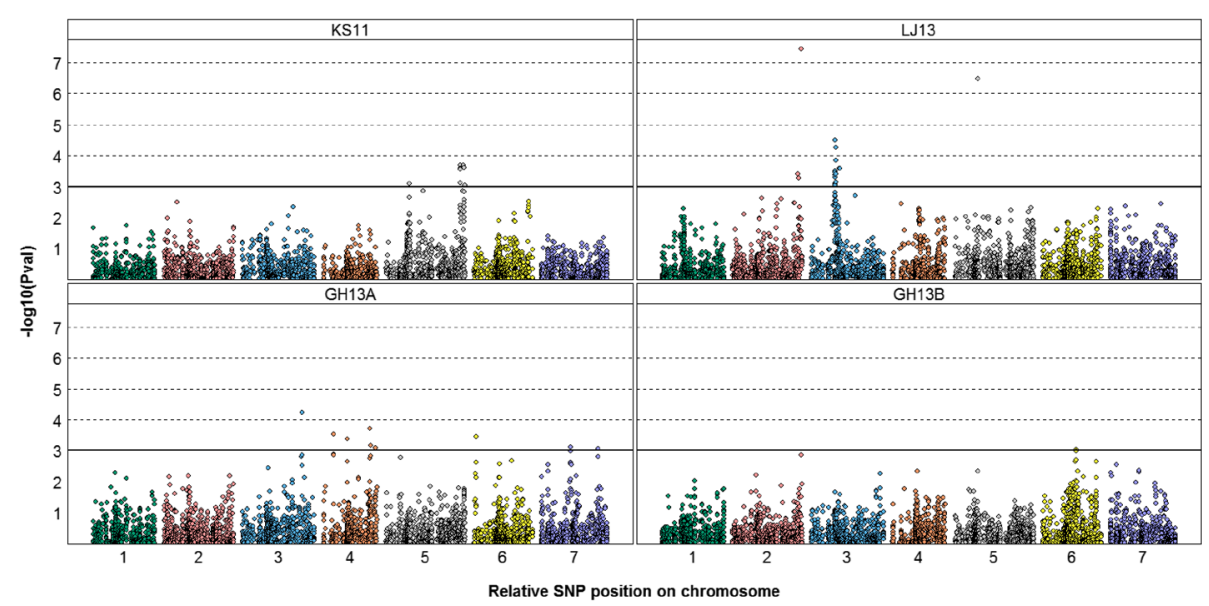

Fig. 5 Manhattan plot of GWA on $F_{V} / F_{M}$ value for four environments. Each point represents one SNP over the seven barley chromosomes, with its chromosome position on $x$-axis and its $-\log _{10}\left(P_{\text {val }}\right)$ associated on $y$-axis. The horizontal bar $\left(-\log _{10}\left(P_{\mathrm{Val}}\right)=3\right)$ represents a P-value of 0.001 . The environments are field: KS11 and L13 and greenhouse GH13A and GH13B

\section{Germin proteins}

Germin and germin-like proteins (GLP) coding genes were identified in GH13A in two different positions on chromosome $4 \mathrm{H}$. For the $\mathrm{F}_{\mathrm{V}} / \mathrm{F}_{\mathrm{M}}$ parameter (Table 6), SNP SCRI_RS_98443 was detected $\left(-\log _{10}\left(\mathrm{P}_{\text {val }}\right)=3.5\right)$ at 22.2 cM whereas the coding gene MLOC_75098.2 is located at $18.5 \mathrm{cM}$. The second association was identified by the SNPs SCRI_RS_157125 and SCRI_RS_235762 $\left(-\log _{10}\left(\mathrm{P}_{\mathrm{val}}\right)=3.1\right)$ both at position $111.3 \mathrm{cM}$. The GLP coding gene AK367749 was detected at the same position.

\section{$M n-S O D$}

The manganese superoxide dismutase (Mn-SOD) gene was identified in GH13A and LJ13 on chromosome $7 \mathrm{H}$. Associations were found for $\mathrm{V}_{\mathrm{I}}$ with SNP SCRI_RS_158266 located at $12.8 \mathrm{cM}\left(-\log _{10}\left(\mathrm{P}_{\mathrm{val}}\right)=\right.$ 3.1 ) at the exact same position of the coding gene MLOC_69817.1 (Additional file 4).

\section{Photosystem I subunits}

Photosystem I (PSI) coding genes were found by GWA. Of these, PsaA/PsaB were found with the coding gene MLOC_40094.1 in GH13A for the $F_{V} / F_{M}$ trait on chromosome $4 \mathrm{H}$ at $99.1 \mathrm{cM}$. SNP 12_30987 was detected as the most significant association $\left(-\log _{10}\left(\mathrm{P}_{\mathrm{val}}\right)=\right.$ 3.7 ) at the position $100.6 \mathrm{cM}$ (Table 6). In addition to these QTLs, PsaH (MLOC_53469.2) and PsaE (MLOC_73050.2) were detected for $V_{I}$ with SNPs 11_20908 (1H) and SCRI_RS_2824 respectively. They were 1 and $0 \mathrm{cM}$ away from their respective genes. Finally, PsaN (AK368803) was identified with SNP $1121057(2 \mathrm{H})$ at $0.1 \mathrm{cM}$ from the marker position (Additional file 4).

\section{Chlorophyll $a / b$ binding protein}

Genes coding for Chlorophyll $a / b$ protein were identified for many associated SNPs on chromosomes $1 \mathrm{H}$, $5 \mathrm{H}, 6 \mathrm{H}$ and $7 \mathrm{H}$, in several copies and for all fluorescence parameters (Additional file 4). These proteins are also known as light-harvesting chlorophyll $a / b$ binding (Lhc) proteins in higher plants and green algae.

\section{Protein phosphatase 2C (PP2C) Mn/Mg aspartate binding} Many other SNPs were found to be significant and colocalized with PP2C genes. They were found in chromosomes $1 \mathrm{H}, 2 \mathrm{H}, 3 \mathrm{H}, 4 \mathrm{H}$ and $7 \mathrm{H}$ for all fluorescence parameters (Table 6, Additional file 4). From the GWA results, multiple copies of these genes were identified.

\section{Discussion}

\section{Quantification of Mn deficiency}

Chl $a$ fluorescence has previously been shown to be a powerful tool to quantify the severenes of Mn deficiency in plants $[3,6,21]$. However, little is known about differences in Mn uptake and Mn tissue concentrations in the plant tissue of varieties with contrasting Mn efficiency. Therefore, the quantification of $\mathrm{Mn}$ in leaves was used as an additional parameter.in the current study. Plants were clearly Mn deficient as indicated by the leaf tissue concentrations ranging from7-12 $\mu \mathrm{g}^{-1} \mathrm{Mn} \mathrm{g}$ DW [21].

However, the correlation, 0.59 , between Mn concentration and $\mathrm{F}_{\mathrm{V}} / \mathrm{F}_{\mathrm{M}}$ does not suggest a strong link between the two parameters. GWA did not reveal any strong association with tissue $\mathrm{Mn}$ as indicated by the absence of a correlation between leaf Mn concentrations and the functional pool of Mn in PSII using Fv/ Fm values as a proxy. 
Table 6 Summary of significant $\left(-\log _{10}\left(P_{V a l}\right) \geq 3\right)$ marker-trait associations identified by GWA based on the $F_{V} / F_{M}$ trait and the corresponding candidate genes from the Blast results

\begin{tabular}{|c|c|c|c|c|c|c|c|c|c|c|}
\hline \multirow[t]{2}{*}{ Environment } & \multirow[t]{2}{*}{ Marker name } & \multicolumn{2}{|c|}{ Position } & \multicolumn{4}{|c|}{ GWA statistics } & \multicolumn{3}{|l|}{ BLAST results } \\
\hline & & $\overline{\mathrm{Chr}}$ & CM & $-\log _{10}(P)$ & $\mathrm{MAF}^{\mathrm{a}}$ & Effect & $\mathrm{SE}^{\mathrm{b}}$ & Gene & $\mathrm{CM}$ & Description \\
\hline \multirow[t]{13}{*}{$\mathrm{GH} 13 \mathrm{~A}$} & 12_30482 & $3 \mathrm{H}$ & 128.6 & 4.2 & 0.26 & 0.014 & 0.003 & - & - & - \\
\hline & SCRI_RS_98443 & $4 \mathrm{H}$ & 22.2 & 3.5 & 0.17 & 0.016 & 0.004 & MLOC_75098.2 & 18.5 & Cupin 1; Germin, Mn binding site \\
\hline & 12_30239 & & 51.0 & 3.4 & 0.14 & -0.015 & 0.004 & MLOC_82113.1 & 49.7 & PSII PsbN \\
\hline & & & & & & & & AK357955 & 54.3 & $\begin{array}{l}\text { Protein phosphatase } 2 \mathrm{C}(\mathrm{PP} 2 \mathrm{C}) \mathrm{Mn} / \mathrm{Mg} \\
\text { aspartate binding site }\end{array}$ \\
\hline & SCRI_RS_142924 & & 51.0 & 3.4 & 0.14 & -0.015 & 0.004 & AK249774.1 & 54.3 & PSII PsbP, oxygen evolving complex \\
\hline & 12_30987 & & 100.6 & 3.7 & 0.43 & 0.012 & 0.003 & MLOC_40094.1 & 99.1 & PSI PsaA/PsaB \\
\hline & SCRI_RS_131671 & & 101.6 & 3.2 & 0.43 & 0.011 & 0.003 & & & \\
\hline & SCRI_RS_157125 & & 111.3 & 3.1 & 0.13 & -0.015 & 0.004 & AK367749 & 111.3 & Cupin 1; Germin, Mn binding site \\
\hline & SCRI_RS_235762 & & 111.3 & 3.1 & 0.13 & -0.015 & 0.004 & & & \\
\hline & SCRI_RS_56 & $6 \mathrm{H}$ & 4.9 & 3.4 & 0.30 & 0.011 & 0.003 & - & - & - \\
\hline & 12_30149 & 7H & 62.4 & 3.1 & 0.36 & 0.011 & 0.003 & - & - & - \\
\hline & SCRI_RS_184488 & & 120.8 & 3.1 & 0.01 & 0.039 & 0.011 & MLOC_3173.4 & 124.6 & PP2C Mn/Mg aspartate binding site \\
\hline & & & & & & & & MLOC_77860.1 & 124.6 & PSII PsbP, oxygen evolving complex \\
\hline $\mathrm{GH} 13 \mathrm{~B}$ & SCRI_RS_144892 & $6 \mathrm{H}$ & 72.2 & 3.1 & 0.30 & -0.013 & 0.004 & - & - & - \\
\hline \multirow[t]{9}{*}{ KS11 } & SCRI_RS_137249 & $5 \mathrm{H}$ & 50.0 & 3.1 & 0.13 & -0.019 & 0.005 & AK368229 & 47.9 & Chlorophyll $a / b$ binding protein \\
\hline & & & & & & & & MLOC_18354.1 & 51.3 & Chlorophyll $a / b$ binding protein \\
\hline & 11_10254 & & 159.5 & 3.7 & 0.13 & -0.021 & 0.006 & AK251925.1 & 159.5 & PSII Psb28, class 1 \\
\hline & SCRI_RS_199298 & & 159.5 & 3.1 & 0.13 & 0.019 & 0.006 & & & \\
\hline & SCRI_RS_235652 & & 159.5 & 3.6 & 0.13 & 0.020 & 0.005 & & & \\
\hline & 11_10870 & & 159.5 & 3.6 & 0.12 & 0.022 & 0.006 & & & \\
\hline & SCRI_RS_237948 & & 167.6 & 3.7 & 0.36 & -0.015 & 0.004 & - & - & - \\
\hline & SCRI_RS_174123 & & 167.7 & 3.6 & 0.31 & -0.015 & 0.004 & & & \\
\hline & SCRI_RS_239569 & & 169.4 & 3.0 & 0.50 & -0.012 & 0.004 & & & \\
\hline \multirow[t]{19}{*}{ LJ13 } & 12_30823 & $2 \mathrm{H}$ & 140.8 & 3.4 & 0.11 & 0.019 & 0.005 & - & - & - \\
\hline & SCRI_RS_73620 & & 142.3 & 3.3 & 0.40 & -0.015 & 0.004 & & & \\
\hline & SCRI_RS_231015 & & 147.3 & 7.4 & 0.18 & -0.027 & 0.005 & & & \\
\hline & 12_30002 & $3 \mathrm{H}$ & 51.4 & 3.5 & 0.33 & -0.025 & 0.007 & MLOC_38362.2 & 51.6 & Chlorophyll $a / b$ binding protein \\
\hline & 12_31372 & & 51.4 & 3.5 & 0.32 & -0.025 & 0.007 & & & \\
\hline & 11_10365 & & 51.6 & 4.5 & 0.32 & 0.029 & 0.007 & & & \\
\hline & SCRI_RS_173348 & & 51.6 & 3.1 & 0.32 & -0.023 & 0.007 & & & \\
\hline & 11_20890 & & 51.6 & 3.3 & 0.32 & 0.024 & 0.007 & & & \\
\hline & 11_20102 & & 51.6 & 3.5 & 0.32 & 0.025 & 0.007 & & & \\
\hline & SCRI_RS_137552 & & 51.6 & 3.5 & 0.32 & 0.025 & 0.007 & & & \\
\hline & SCRI_RS_186504 & & 51.6 & 3.5 & 0.32 & 0.025 & 0.007 & & & \\
\hline & 11_10224 & & 51.7 & 3.5 & 0.33 & 0.025 & 0.007 & & & \\
\hline & SCRI_RS_238114 & & 51.8 & 3.4 & 0.33 & -0.024 & 0.007 & AK374059 & 52.6 & PP2C Mn/Mg aspartate binding site \\
\hline & 11_10349 & & 51.8 & 3.1 & 0.33 & 0.023 & 0.007 & & & \\
\hline & 12_31011 & & 52.1 & 3.1 & 0.35 & 0.019 & 0.006 & & & \\
\hline & 12_31393 & & 52.6 & 3.4 & 0.33 & 0.021 & 0.006 & & & \\
\hline & $11 \_21511$ & & 52.6 & 4.3 & 0.35 & 0.025 & 0.006 & & & \\
\hline & 11_20276 & & 52.9 & 3.4 & 0.33 & 0.021 & 0.006 & & & \\
\hline & 11_20325 & & 53.1 & 3.1 & 0.32 & -0.020 & 0.006 & & & \\
\hline
\end{tabular}


Table 6 Summary of significant $\left(-\log _{10}\left(P_{v a l}\right) \geq 3\right)$ marker-trait associations identified by GWA based on the $F_{V} / F_{M}$ trait and the corresponding candidate genes from the Blast results (Continued)

\begin{tabular}{llllllllll}
\hline 11_10225 & 53.3 & 3.8 & 0.33 & -0.022 & 0.006 & & & \\
SCRI_RS_201987 & 59.6 & 3.6 & 0.28 & 0.016 & 0.004 & - & - & - \\
SCRI_RS_76971 & & 61.7 & 3.6 & 0.28 & 0.016 & 0.004 & AK369292 & 68.2 & PSII PsbW, class 2 \\
11_21414 & $5 H$ & 49.9 & 6.5 & 0.21 & 0.023 & 0.004 & AK368229 & 47.9 & Chlorophyll a/b binding protein \\
& & & & & & & MLOC_18354.1 & 51.3 & Chlorophyll a/b binding protein \\
\hline
\end{tabular}

${ }^{a}$ Minor Allele Frequency

bstandard error

Allelic effect sign is estimated with respect to the minor allele. SNPs are ordered by environment and genome position

\section{Environment-specific QTLs}

Mn efficiency appears to be a complex quantitative trait controlled by many genes, each contributing with minor effects. Genetic determination of the trait ranged between 0.18 and 0.31 in the four environments analysed (Table 4 ), which means that only $18 \%$ to $31 \%$ of the phenotypic variance was due to the genetic variance. This supports the variability of plant responses to $\mathrm{Mn}$ deficiency partly being determined by genetic background. However, in contrast to traits governed by a few loci with large effects, the variation in quantitative traits is caused by the segregation of multiple QTL with individually small effects that are sensitive to the environment [68]. Indeed, significantly associated SNPs were found with relatively small effects (0.011 to 0.039$)$ for $\mathrm{F}_{\mathrm{V}} / \mathrm{F}_{\mathrm{M}}$ (Table 6). Those markers are identified only within specific environments and the corresponding QTLs are consequently specifically related to a single environment. Collins et al. [13] introduced the concept of "constitutive" and "adaptive" QTLs controlling the response of crops to abiotic stress. A "constitutive" QTL is consistently detected across different environments whereas "adaptive" QTL is environment-specific. Stress sensitivity can therefore be due to the responsiveness of QTL regulation in specific environmental conditions or due to indirect causes contributing to the stress response. Staple or constitutive QTLs are naturally preferred in breeding.

In association mapping, detecting constitutive QTLs for abiotic stresses is challenging, since QTL effects are most likely small and controlled by one or several genes, and by epistasis and environments. Environment-specific QTL has been previously reported in cereals, in winter barley [69], in wheat [70, 71], and in rice [72]. In the case of the Mn efficiency trait, the four environments included, had varying characteristics due to various climates in the three different years, differences in soil conditions and/or different growth stages at the screening date (Table 1).

Moreover, poor genetic correlations between environments also support the environment-specific feature of the trait, with correlations in a range from -0.11 to 0.61 for the four environments analysed (Table 4).
Nevertheless, with a genetic correlation of 0.61 , the two greenhouse experiments imply that Mn efficiency in GH13A and GH13B was regulated by a set of shared genes under the controlled environmental conditions, with identical soil and comparable climates.

The results confirmed that environments have to be considered independently for the complex Mn efficiency trait. Consequently, different environmental conditions are needed to obtain a comprehensive picture of the trait and to identify the "adaptive" QTLs contributing to Mn efficiency.

\section{Identification of candidate genes}

Combining GWA, database screening and prior knowledge about the role of $\mathrm{Mn}$ in plants allowed several candidate genes to be identified, coding for PSI and PSII proteins, chlorophyll $a / b$ binding proteins, GLP, Mn-SOD, and PP2C. Two different classes of encoding genes could be distinguished, the first related to photosynthesis and the others involved in various $\mathrm{Mn}$ dependent pathways.

In photosynthesis, reactions occur in the thylakoid membranes carried out by multi-protein complexes, namely ATP synthase, PSI, PSII, cytochrome $b 6 f$ and light harvesting complexes. Proteins from these complexes were identified: chlorophyll $a / b$ binding proteins, PsaA/PsaB, PsaE, PsaH and PsaN from PSI; Psb28, PsbN, PsbP, PsbQ and PsbW from PSII; and finally Lhc proteins in multiple copies at several genome positions.

\section{Role of $\mathrm{Mn}$ in metabolic pathways}

The light-harvesting chlorophyll $a / b$ binding proteins belong to the Lhc family consisting of more than 20 different proteins and are connected with PSI and PSII [73]. Their primary function is related to the absorption of light through chlorophyll excitation and the transfer of the absorbed energy to photochemical reaction centres. Although Lhc are coded by well characterized and abundant CAB (chlorophyll a/b binding) genes [74, 75], the link to Mn metabolism is not trivial. Nevertheless, previous studies showed a reduction in Chl $a$ concentration in Mn deficient plants and changes in the phosphorylated forms of LhcII have been observed [21]. 
Several protein subunits from PSI were also detected. Similarly to the chlorophyll $a / b$ binding proteins there is no obvious and immediate links to Mn utilization. The subunits PsaA/PsaB are involved in electron transport and form the core centre of PSI [76]. PsaE is one of the three stromal subunits of PSI whereas PsaH and PsaN are specific plants subunits $[77,78]$. Although $\mathrm{Mn}$ is not a PSI cofactor, a decrease in the PSI activity in Mn-limited conditions has been reported previously. The composition of the PSI complex is altered and a decrease in PsaA subunit is pronounced [79].

PSII consists of at least 20 protein subunits and catalyses a light-driven process, splitting water into protons and molecular oxygen. $[75,80]$. The Psb28 protein is associated with the cytoplasmic side of the thylakoid membrane and known to interact with the core protein CP43 in the PSII monomer [81]. Even though no direct link with Mn has been demonstrated, recent studies have partly established its function. A Psb28 deletion mutant generated in Synechocystis showed slower growth rates and lower chlorophyll levels. [81, 82]. Recent studies suggest a role of Psb28 in the assembly and repair of PSII under heat stress [83, 84].

In barley, PsbP and PsbQ subunits are extrinsic proteins involved in the stabilization of the tetranuclear Mn cluster of OEC. [85, 86]. The crucial role of PsbP in Mn binding to PSII has already been established [87]. It has been described as a Mn storage protein delivering $\mathrm{Mn}^{2+}$ during PSII assembly. Its absence slows down the process of photoactivation. Whereas PsbP was found mandatory for OEC activity and showed a strong Mn dependence, PsbQ did not present a manganese-dependent activity [88]. However, recent studies established that PsbQ stabilizes PsbP binding and therefore contributes to the activity of the OEC in PSII complexes [89]. Finally, a study on the tobacco PsbQ mutant revealed the effect of PsbQ loss on Chl a fluorescence under low light conditions. For the PsbQ mutant, $\mathrm{F}_{\mathrm{V}} / \mathrm{F}_{\mathrm{M}}$ dropped from 0.73 to 0.26 under low light conditions [90]. Hence, measuring Mn efficiency based on Chl $a$ fluorescence appears to be linked to PsbQ activity. PsbN, a low molecular subunit encoded in the chloroplast, has exclusively been found in etioplasts, but its PSII function remains elusive [91]. Nevertheless, a recent study has demonstrated by reverse genetics in tobacco, that PsbN is involved in the biogenesis of PSI and PSII [92]. In addition, it has been demonstrated that PsbN is required for the repair and assembly of PSII [93].

Recent work with PsbW knock-out and antisense Arabidopsis mutants indicated an important role played by PsbW for the connection and stability of PSII-LHCII complexes [94]. Lower $\mathrm{F}_{\mathrm{V}} / \mathrm{F}_{\mathrm{M}}$ values have been reported for mutants lacking PsbW, but despite the role of PsbW for the PSII complex, direct effects of Mn on PsbW remain unclear.
The identification of several candidate genes coding for PSII subunit proteins (PsbN, PsbP, PsbQ and PsbW) demonstrate that $\mathrm{Mn}$ is involved in the stability, in the assembly and repair of the PSII and in the loading of $\mathrm{Mn}$ into the photosystem machinery. Therefore, it suggests that some varieties are able to load Mn, assembly PSII and repair PSII better than other under Mn deficient condition.

Apart from photosystem related proteins, two other types of proteins were found to be involved in Mn efficiency: PP2C and GLP. PP2C is a well-known serine/ threonine specific protein phosphatase. With 76 candidate genes identified in Arabidopsis [95], the PP2C family is considered the largest protein phosphatase family in plants. They are identified on several barley chromosomes $(1 \mathrm{H}, 2 \mathrm{H}, 3 \mathrm{H}, 4 \mathrm{H}$ and $7 \mathrm{H})$. These phosphatases are involved in the regulation of several signalling pathways and stress responses in plants [96]. In the current context, an interesting feature of $\mathrm{PP} 2 \mathrm{C}$ is the relatively high concentration of $\mathrm{Mn}$ or $\mathrm{Mg}$ required to maintain activity. In moss Physcomitrella patens, the activation of PP2C occurs at $0.1 \mathrm{mM}$ of $\mathrm{Mn}$ whereas more than $5 \mathrm{mM}$ of $\mathrm{Mg}$ was needed to activate the protein [97]. It therefore suggests that $\mathrm{Mn}$ has a special feature in activating PP2C, which appears to be a factor influencing Mn efficiency.

The remaining genes identified by GWA are coding for GLP and Mn-SOD. GLP are often described in crops as having two main enzymatic functions, OxO and SOD, in response to biotic and abiotic stress $[98,99]$. The two enzymes, $\mathrm{Mn}$-SOD and $\mathrm{OxO}$, generate hydrogen peroxide $\left(\mathrm{H}_{2} \mathrm{O}_{2}\right)$, a signalling molecule in plant defence. OxO enzymes are localized in the apoplast and Mn-SOD in mitochondria; they work in antioxidant defence by enzymatic mechanisms scavenging reactive oxygen species (ROS). A first study demonstrated the involvement of $\mathrm{Mn}$ as a cofactor in barley OxO activity [26]. Hence, it has been confirmed by spectroscopy and crystallography that $\mathrm{Mn}$ is a required cofactor for $\mathrm{OxO}$ catalysis [100, 101]; moreover it revealed the Mn-SOD activity of GLP. GLP coding genes in barley are mapped on chromosomes $2 \mathrm{H}, 3 \mathrm{H}, 4 \mathrm{H}$, $5 \mathrm{H}, 7 \mathrm{H}$ and classifies to five main subfamilies annotated $H \nu$ GER-I to $H \nu$ GER-V [102]. Finally, gene family studies on barley $[103,104]$ confirmed the OxO and SOD activity of GLP, their function in defence resistance, the duplication of GLP genes, their developmental stage and their tissue-specific expression. The excellent characterization of the barley GLP genes and activity may contribute to a better understanding of the role of Mn.

\section{Conclusions}

Mn deficiency was the sole cause for the decrease in quantum yield efficiency $\left(\mathrm{F}_{\mathrm{V}} / \mathrm{F}_{\mathrm{M}}\right)$. The combination of Chl $a$ fluorescence analysis and GWA approaches used in the current study has unravelled a series of main 
components contributing to the polygenic trait for $\mathrm{Mn}$ efficiency and paves the way for a better genetic characterization of the trait. Several putative QTLs anchored in various chromosomes pointed out genes coding for proteins which have a clear Mn dependency. First of all, multiple PSI and PSII candidate genes were identified of which PsbP is known to be directly involved in a $\mathrm{Mn}$ dependent regulation of PSII activity, whereas other photosystem subunits PsbQ, PsbN and Psb28 are important for maintaining the catalytic properties of the Mn cofactor in OEC r. Furthermore, two other types of genes coding for Mn dependent proteins were identified: GLP and PP2C genes. Both proteins are involved in stress signalling pathways. Even though the candidate genes needs to be confirmed by molecular approaches such as fine mapping, gene expression or mutant studies, the current study identifies a series of important candidate genes, suitable for future investigations into the genetic components controlling differential Mn efficiency in plants.

\section{Additional files}

Additional file 1: List of the 248 winter barley varieties. (PDF $24 \mathrm{~kb}$ )

Additional file 2: Figure of elemental profiles of the controls plants in $\sqcup \mathrm{J} 13 \mathrm{in} \mu \mathrm{g} . \mathrm{g}^{-1}$ of leaf dry weight and their standard error bars. (PDF $20 \mathrm{~kb}$ )

Additional file 3: Table of GWA results for Mn concentration. (PDF $13 \mathrm{~kb}$ )

Additional file 4: Table of GWA results for JIP parameters. (PDF $49 \mathrm{~kb}$ )

\section{Abbreviations}

BLUP: Best linear unbiased predictors; Chl a: Chlorophyll a; CV\%: Coefficient of variation; GLP: Germin-like protein; GWA: Genome-wide association study; $\mathrm{H}^{2}$ : Genetic determination of the trait; ICP-OES: Inductively coupled plasma optical emission spectrometry; LD: Linkage disequilibrium; Lhc: Light-harvesting chlorophyll a/b binding; LOQ: Limit of quantification; MAF: Minor allele frequencies; Mn: Manganese; Mn-SOD: Mn superoxide dismutase; OEC: Oxygen-evolving complex; OxO: Oxalate-oxidase; PAL: Phenylalanine ammonia-lyase; PP2C: Protein phosphatase 2C; PSI: Photosystem I; PSII: Photosystem II; ROS: Reactive oxygen species; SNP: Single nucleotide polymorphism

\section{Acknowledgments}

The authors acknowledge the Danish Strategic Research Council which funded Nutriefficient (Grant no: 10-093498), Sejet Plant Breeding and Rasmus Lund Hjortshøj for their participation and for providing barley lines from their research program. We thank Laura Rossini and Alessandro Tondelli from the University of Milan and Genomic Research Centre (Fiorenzuola) for providing seed and additional genomic data.

\section{Availability of data and materials}

The raw data, including phenotype and genotype data cannot be made freely available as the population to a significant extent belongs to commercial plant breeding companies. However, the corresponding author will seek to provide data for specific demands upon request.

\section{Authors' contributions}

PP, SH, SR designed the study and conceived the project "Nutriefficient". FL conducted the experimental work and performed data analysis. PP and SH supervised the experimental work and participated in data interpretation. All authors reviewed and contributed to draft the manuscript. All authors read and approved the final manuscript.

\section{Competing interests}

The authors declare that they have no competing interests.

Received: 9 April 2016 Accepted: 27 September 2016

Published online: 04 October 2016

\section{References}

1. Reuter D, Cartwright B, Judson G, McFarlane J, Maschmedt D, Robinson J. Trace elements in South Australian agriculture. Department of Agriculture South Australia, Technical Report no 139. 1988.

2. Welch RM, Allaway WH, House WA, Kubota J, Luxmoore R. Geographic distribution of trace element problems. Micronutrients in agriculture. 1991 (Ed. 2). p. 31-57.

3. Hebbern CA, Pedas P, Schjoerring JK, Knudsen L, Husted S. Genotypic differences in manganese efficiency: field experiments with „winter barley (Hordeum vulgare L.). Plant and Soil. 2005;272(1-2):233-44.

4. Yang $X E$, Chen WR, Feng $Y$. Improving human micronutrient nutrition through biofortification in the soil-plant system: China as a case study. Environ Geochem Health. 2007;29(5):413-28.

5. Broadley M, Brown P, Cakmak I, Rengel Z, Zhao F. Chapter 7 - Function of Nutrients: Micronutrients. In: Marschner $P$, editor. Marschner's Mineral Nutrition of Higher Plants (Third Edition). San Diego: Academic; 2012. p. 191-248.

6. Schmidt SB, Pedas P, Laursen KH, Schjoerring JK, Husted S. Latent manganese deficiency in barley can be diagnosed and remediated on the basis of chlorophyll a fluorescence measurements. Plant and Soil. 2013;372(1-2):417-29.

7. Burnell JN. The biochemistry of manganese in plants. In: "Manganese in soils and plants" (eds. Graham, RD, Hannam, RJ and Uren, NC). Springer; 1988. p. 125-37.

8. Rengel Z, Graham RD, Pedler JF. Time-Course of Biosynthesis of Phenolics and Lignin in Roots of Wheat Genotypes Differing in Manganese Efficiency and Resistance to Take-All Fungus. Ann Bot-London. 1994;74(5):471-7.

9. Brennan RF. The Role of Manganese and Nitrogen Nutrition in the Susceptibility of Wheat Plants to Take-All in Western-Australia. Fertilizer Res. 1992;31(1):35-41.

10. Stoltz E, Wallenhammar AC. Manganese application increases winter hardiness in barley. Field Crop Res. 2014;164:148-53.

11. White PJ, Greenwood DJ. Properties and management of cationic elements for crop growth. In: Soil Conditions and Plant Growth. Blackwell Publishing Ltd; 2013. p. 160-94

12. Ascher-Ellis J, Graham RD, Hollamby G, Paull JG, Davies P, Huang C, et al. Micronutrients. 2001.

13. Collins NC, Tardieu F, Tuberosa R. Quantitative trait loci and crop performance under abiotic stress: Where do we stand? Plant Physiol. 2008;147(2):469-86.

14. Rengel Z. Genotypic Differences in Micronutrient Use Efficiency in Crops. Commun Soil Sci Plant Anal. 2007;32(7-8):1163-86.

15. Chin JH, Gamuyao R, Dalid C, Bustamam M, Prasetiyono J, Moeljopawiro S, et al. Developing rice with high yield under phosphorus deficiency: Pup1 sequence to application. Plant Physiol. 2011;156(3):1202-16.

16. Gamuyao R, Chin JH, Pariasca-Tanaka J, Pesaresi P, Catausan S, Dalid C, et al. The protein kinase Pstol1 from traditional rice confers tolerance of phosphorus deficiency. Nature. 2012;488(7412):535-9.

17. Graham R. Genotypic Differences in Tolerance to Manganese Deficiency. In: Graham R, Hannam R, Uren N, editors. Manganese in Soils and Plants, vol. 33. Netherlands: Springer; 1988. p. 261-76.

18. Pedas P, Hebbern CA, Schjoerring JK, Holm PE, Husted S. Differential capacity for high-affinity manganese uptake contributes to differences between barley genotypes in tolerance to low manganese availability. Plant Physiol. 2005;139(3):1411-20.

19. Pedas P, Ytting CK, Fuglsang AT, Jahn TP, Schjoerring JK, Husted S. Manganese efficiency in barley: identification and characterization of the metal ion transporter HvIRT1. Plant Physiol. 2008;148(1):455-66.

20. Socha AL, Guerinot ML. Mn-euvering manganese: the role of transporter gene family members in manganese uptake and mobilization in plants. Front Plant Sci. 2014;5:106.

21. Husted S, Laursen KH, Hebbern CA, Schmidt SB, Pedas P, Haldrup A, et al. Manganese deficiency leads to genotype-specific changes in fluorescence induction kinetics and state transitions. Plant Physiol. 2009:150(2):825-33.

22. Schmidt SB, Persson DP, Powikrowska M, Frydenvang J, Schjoerring JK, Jensen $\mathrm{PE}$, et al. Metal binding in photosystem II super-and subcomplexes from barley thylakoids. Plant Physiol. 2015;168(4):1490-502. 
23. George TS, French AS, Brown LK, Karley AJ, White PJ, Ramsay L, et al. Genotypic variation in the ability of landraces and commercial cereal varieties to avoid manganese deficiency in soils with limited manganese availability: is there a role for root-exuded phytases? Physiologia plantarum. 2014;151(3):243-256.

24. White AR, Xin Y, Pezeshk V. Xyloglucan glucosyltransferase in Golgi membranes from Pisum sativum (pea). Biochem J. 1993;294(Pt 1):231-8.

25. Nunan KJ, Scheller HV. Solubilization of an arabinan arabinosyltransferase activity from mung bean hypocotyls. Plant Physiol. 2003;132(1):331-42.

26. Requena L, Bornemann S. Barley (Hordeum vulgare) oxalate oxidase is a manganese-containing enzyme. Biochem J. 1999;343(1):185-90.

27. Bowler C, Slooten L, Vandenbranden S, Derycke R, Botterman J, Sybesma C, et al. Manganese Superoxide-Dismutase Can Reduce Cellular-Damage Mediated by Oxygen Radicals in Transgenic Plants. Embo J. 1991;10(7):1723-32.

28. Alscher RG, Erturk N, Heath LS. Role of superoxide dismutases (SODs) in controlling oxidative stress in plants. J Exp Bot. 2002;53(372):1331-41.

29. Govindjee G. Chlorophyll a fluorescence: a bit of basics and history. Chlorophyll a fluorescence: a signature of photosynthesis Springer, Dordrecht. 2004:1-42

30. Hall D, Tegstrom C, Ingvarsson PK. Using association mapping to dissect the genetic basis of complex traits in plants. Brief Funct Genomics. 2010;9(2):157-65.

31. Rafalski JA. Association genetics in crop improvement. Curr Opin Plant Biol. 2010;13(2):174-80

32. Wang J, McClean PE, Lee R, Goos RJ, Helms T. Association mapping of iron deficiency chlorosis loci in soybean (Glycine max L. Merr.) advanced breeding lines. Theor Appl Gen. 2008;116(6):777-87.

33. Lonergan PF, Pallotta MA, Lorimer M, Paull JG, Barker SJ, Graham RD. Multiple genetic loci for zinc uptake and distribution in barley (Hordeum vulgare). New Phytol. 2009;184(1):168-79.

34. Genc Y, Verbyla AP, Torun AA, Cakmak I, Willsmore K, Wallwork H, et al. Quantitative trait loci analysis of zinc efficiency and grain zinc concentration in wheat using whole genome average interval mapping. Plant and Soil. 2008:314(1-2):49-66

35. Waters BM, Grusak MA. Quantitative trait locus mapping for seed mineral concentrations in two Arabidopsis thaliana recombinant inbred populations. New Phytol. 2008;179(4):1033-47.

36. McCarthy K, Longnecker N, Sparrow D, Graham R: Inheritance of manganese efficiency in barley (Hordeum vulgare L.). In. International Symposium on Manganese in Soils and Plants: Contributed Papers MJ Webb, RO Nable, RD Graham, and RJ Hannam (eds) Manganese Symposium, Adelaide: 1988; 1988: 121-122

37. Pallotta MA, Graham RD, Langridge P, Sparrow DHB, Barker SJ. RFLP mapping of manganese efficiency in barley. Theor Appl Genet. 2000;101(7):1100-8.

38. Pallotta MA, Asayama S, Reinheimer JM, Davies PA, Barr AR, Jefferies SP, et al. Mapping and QTL analysis of the barley population Amagi Nijo $x$ WI2585. Aust J Agr Res. 2003:54(11-12):1141-4.

39. FAO. FAOSTAT. FAO: Rome; 2014.

40. Newton AC, Flavell AJ, George TS, Leat P, Mullholland B, Ramsay L, et al. Crops that feed the world 4. Barley: a resilient crop? Strengths and weaknesses in the context of food security. Food Secur. 2011;3(2):141-78.

41. Salse J, Abrouk M, Bolot S, Guilhot N, Courcelle E, Faraut T, et al. Reconstruction of monocotelydoneous proto-chromosomes reveals faster evolution in plants than in animals. Proc Natl Acad Sci U S A. 2009;106(35):14908-13.

42. IBGSC. A physical, genetic and functional sequence assembly of the barley genome. Nature. 2012;491(7426):711-6.

43. Munoz-Amatriain M, Cuesta-Marcos A, Hayes PM, Muehlbauer GJ. Barley genetic variation: implications for crop improvement. Brief Funct Genomics. 2014;13(4):341-50.

44. Rizza F, Pagani D, Stanca AM, Cattivelli L. Use of chlorophyll fluorescence to evaluate the cold acclimation and freezing tolerance of winter and spring oats. Plant Breeding. 2001;120(5):389-96

45. Strasser R, Tsimilli-Michael M, Srivastava A. Analysis of the Chlorophyll a Fluorescence Transient. In: Govindjee PG, editor. Chlorophyll a Fluorescence, vol. 19. Netherlands: Springer; 2004. p. 321-62.

46. Baker NR, Rosenqvist E. Applications of chlorophyll fluorescence can improve crop production strategies: an examination of future possibilities. J Exp Bot. 2004;55(403):1607-21.

47. R Core Development Team. R: A Language and Environment for Statistical Computing. 2014
48. Gilmour AR, Thompson R, Cullis BR. Average information REML: An efficient algorithm for variance parameter estimation in linear mixed models. Biometrics. 1995;51(4):1440-50.

49. Butler DG, Cullis BR, Gilmour AR, Gogel BJ. ASReml-R reference manual, release 3. In: Brisbane: Queensland Department of Primary Industries and Fisheries. 2009.

50. Piepho HP, Möhring J, Melchinger AE, Büchse A. BLUP for phenotypic selection in plant breeding and variety testing. Euphytica. 2007;161(1-2):209-28.

51. Smith AB, Cullis BR, Thompson R. The analysis of crop cultivar breeding and evaluation trials: an overview of current mixed model approaches. J Agr Sci. 2005;143(06):449-62

52. Comadran J, Kilian B, Russell J, Ramsay L, Stein N, Ganal M, et al. Natural variation in a homolog of Antirrhinum CENTRORADIALIS contributed to spring growth habit and environmental adaptation in cultivated barley. Nat Genet. 2012:44(12):1388-92.

53. Pritchard JK, Stephens M, Donnelly P. Inference of population structure using multilocus genotype data. Genetics. 2000;155(2):945-59.

54. Besnier F, Glover KA. ParallelStructure: a R package to distribute parallel runs of the population genetics program STRUCTURE on multi-core computers. Plos One. 2013;8(7):e70651.

55. Evanno G, Regnaut S, Goudet J. Detecting the number of clusters of individuals using the software STRUCTURE: a simulation study. Mol Ecol. 2005;14(8):2611-20.

56. Earl DA. vonHoldt BM. STRUCTURE HARVESTER: a website and program for visualizing STRUCTURE output and implementing the Evanno method. Conserv Genet Resour. 2011;4(2):359-61.

57. Jakobsson M, Rosenberg NA. CLUMPP: a cluster matching and permutation program for dealing with label switching and multimodality in analysis of population structure. Bioinformatics. 2007;23(14):1801-6.

58. Rosenberg NA. distruct: a program for the graphical display of population structure. Mol Ecol Notes. 2003;4(1):137-8.

59. Lipka AE, Tian F, Wang Q, Peiffer J, Li M, Bradbury PJ, et al. GAPIT: genome association and prediction integrated tool. Bioinformatics. 2012;28(18):2397-9.

60. Yu J, Pressoir G, Briggs WH, Vroh Bi I, Yamasaki M, Doebley JF, et al. A unified mixed-model method for association mapping that accounts for multiple levels of relatedness. Nat Genet. 2006:38(2):203-8.

61. Kang HM, Zaitlen NA, Wade CM, Kirby A, Heckerman D, Daly MJ, et al. Efficient control of population structure in model organism association mapping. Genetics. 2008;178(3):1709-23.

62. Loiselle BA, Sork VL, Nason J, Graham C. Spatial Genetic-Structure of a Tropical Understory Shrub, Psychotria Officinalis (Rubiaceae). Am J Bot. 1995:82(11):1420-5.

63. Cantalapiedra CP, Boudiar R, Casas AM, Igartua E, Contreras-Moreira B. BARLEYMAP: physical and genetic mapping of nucleotide sequences and annotation of surrounding loci in barley. Mol Breeding. 2015;35(1):1-11.

64. Bradbury PJ, Zhang Z, Kroon DE, Casstevens TM, Ramdoss Y, Buckler ES. TASSEL: software for association mapping of complex traits in diverse samples. Bioinformatics. 2007;23(19):2633-5.

65. Breseghello F, Sorrells ME. Association mapping of kernel size and milling quality in wheat (Triticum aestivum L.) cultivars. Genetics. 2006;172(2):1165-77.

66. Mundus S, Lombi E, Holm PE, Zhang H, Husted S. Assessing the plant availability of manganese in soils using Diffusive Gradients in Thin films (DGT). Geoderma. 2012;183:92-9.

67. Close TJ, Bhat PR, Lonardi S, Wu Y, Rostoks N, Ramsay L, et al. Development and implementation of high-throughput SNP genotyping in barley. BMC Genomics. 2009;10:582.

68. Mackay TF. The genetic architecture of quantitative traits. Annu Rev Genet. 2001;35(1):303-39.

69. Gutiérrez L, Cuesta-Marcos A, Castro AJ, von Zitzewitz J, Schmitt M, Hayes PM. Association Mapping of Malting Quality Quantitative Trait Loci in Winter Barley: Positive Signals from Small Germplasm Arrays. Plant Genome J. 2011;4(3):256.

70. Kuchel H, Williams K, Langridge P, Eagles HA, Jefferies SP. Genetic dissection of grain yield in bread wheat. II. QTL-by-environment interaction. Theor Appl Gen. 2007;115(7):1015-27.

71. Mathews KL, Malosetti M, Chapman S, Mclntyre L, Reynolds M, Shorter R, et al. Multi-environment QTL mixed models for drought stress adaptation in wheat. Theor Appl Gen. 2008;117(7):1077-91.

72. MacMillan K, Emrich K, Piepho HP, Mullins CE, Price AH. Assessing the importance of genotype $x$ environment interaction for root traits in rice using a mapping population Il: conventional QTL analysis. Theor Appl Gen. 2006;113(5):953-64. 
73. Andersson U, Heddad M, Adamska I. Light stress-induced one-helix protein of the chlorophyll a/b-binding family associated with photosystem I. Plant Physiol 2003;132(2):811-20.

74. Pietrzykowska M, Suorsa M, Semchonok DA, Tikkanen M, Boekema EJ, Aro EM, et al. The light-harvesting chlorophyll a/b binding proteins Lhcb1 and Lhcb2 play complementary roles during state transitions in Arabidopsis. Plant Cell. 2014;26(9):3646-60.

75. Yakushevska AE, Jensen PE, Keegstra W, van Roon H, Scheller HV, Boekema EJ, et al. Supermolecular organization of photosystem II and its associated lightharvesting antenna in Arabidopsis thaliana. Eur J Biochem. 2001;268(23):6020-8.

76. Jensen PE, Bassi R, Boekema EJ, Dekker JP, Jansson S, Leister D, et al. Structure, function and regulation of plant photosystem I. Biochim Biophys Acta. 2007;1767(5):335-52.

77. Dekker JP, Boekema EJ. Supramolecular organization of thylakoid membrane proteins in green plants. Biochim Biophys Acta. 2005;1706(1-2):12-39.

78. Fromme P, Grotjohann I. Structure of Photosystems I and II. In: Schäfer G, Penefsky H, editors. Bioenergetics, vol. 45. Berlin Heidelberg: Springer; 2008. p. 33-72.

79. Salomon E, Keren N. Manganese limitation induces changes in the activity and in the organization of photosynthetic complexes in the cyanobacterium Synechocystis sp. strain PCC 6803. Plant Physiol. 2011;155(1):571-9.

80. Nickelsen J, Rengstl B. Photosystem II assembly: from cyanobacteria to plants. Annu Rev Plant Biol. 2013:64(1):609-35.

81. Dobakova M, Sobotka R, Tichy M, Komenda J. Psb28 protein is involved in the biogenesis of the photosystem II inner antenna CP47 (PsbB) in the cyanobacterium Synechocystis sp. PCC 6803. Plant Physiol. 2009; 149(2):1076-86

82. Shi LX, Hall M, Funk C, Schroder WP. Photosystem II, a growing complex: updates on newly discovered components and low molecular mass proteins. Biochim Biophys Acta. 2012;1817(1):13-25.

83. Mabbitt PD, Wilbanks SM, Eaton-Rye JJ. Structure and function of the hydrophilic Photosystem II assembly proteins: Psb27, Psb28 and Ycf48. Plant Physiol Biochem. 2014;81:96-107.

84. Sakata S, Mizusawa N, Kubota-Kawai H, Sakurai I, Wada H. Psb28 is involved in recovery of photosystem II at high temperature in Synechocystis $\mathrm{sp}$. PCC 6803. Biochim Biophys Acta. 2013;1827(1):50-9.

85. Pagliano C, Saracco G, Barber J. Structural, functional and auxiliary proteins of photosystem II. Photosynth Res. 2013;116(2-3):167-88.

86. Bricker $T M$, Roose JL, Fagerlund RD, Frankel LK, Eaton-Rye JJ. The extrinsic proteins of Photosystem II. Biochim Biophys Acta. 2012;1817(1):121-42.

87. Bondarava N, Un S, Krieger-Liszkay A. Manganese binding to the $23 \mathrm{kDa}$ extrinsic protein of Photosystem II. Biochim Biophys Acta. 2007;1767(6):583-8.

88. Shitov AV, Pobeguts OV, Smolova TN, Allakhverdiev SI, Klimov W. Manganesedependent carboanhydrase activity of photosystem II proteins. Biochemistry Biokhimiia. 2009;74(5):509-17.

89. Kakiuchi S, Uno C, Ido K, Nishimura T, Noguchi T, Ifuku K, et al. The PsbQ protein stabilizes the functional binding of the PsbP protein to photosystem II in higher plants. Biochim Biophys Acta. 2012;1817(8):1346-51.

90. Yi X, Hargett SR, Frankel LK, Bricker TM. The PsbQ protein is required in Arabidopsis for photosystem II assembly/stability and photoautotrophy under low light conditions. J Biol Chem. 2006;281(36):26260-7.

91. Ploscher M, Granvogl B, Zoryan M, Reisinger V, Eichacker LA. Mass spectrometric characterization of membrane integral low molecular weight proteins from photosystem II in barley etioplasts. Proteomics. 2009;9(3):625-35.

92. Krech K, Fu HY, Thiele W, Ruf S, Schottler MA, Bock R. Reverse genetics in complex multigene operons by co-transformation of the plastid genome and its application to the open reading frame previously designated psbN. Plant J. 2013;75(6):1062-74.

93. Torabi S, Umate $\mathrm{P}$, Manavski N, Plochinger M, Kleinknecht L, Bogireddi $\mathrm{H}$, et al. PsbN is required for assembly of the photosystem $I$ reaction center in Nicotiana tabacum. Plant Cell. 2014;26(3):1183-99.

94. Garcia-Cerdan JG, Kovacs L, Toth T, Kereiche S, Aseeva E, Boekema EJ, et al. The PsbW protein stabilizes the supramolecular organization of photosystem II in higher plants. Plant J. 2011;65(3):368-81.

95. Kerk D, Bulgrien J, Smith DW, Barsam B, Veretnik S, Gribskov M. The complement of protein phosphatase catalytic subunits encoded in the genome of Arabidopsis. Plant Physiol. 2002;129(2):908-25.

96. Schweighofer A, Hirt H, Meskiene I. Plant PP2C phosphatases: emerging functions in stress signaling. Trends Plant Sci. 2004;9(5):236-43.
97. Takezawa D. Characterization of a novel plant PP2C-like protein Ser/Thr phosphatase as a calmodulin-binding protein. J Biol Chem. 2003; 278(39):38076-83

98. Dunwell JM, Gibbings JG, Mahmood T, Naqvi SMS. Germin and germin-like proteins: Evolution, structure, and function. Crit Rev Plant Sci. 2008;27(5):342-75.

99. Davidson RM, Reeves PA, Manosalva PM, Leach JE. Germins: A diverse protein family important for crop improvement. Plant Sci. 2009;177(6):499-510.

100. Woo EJ, Dunwell JM, Goodenough PW, Marvier AC, Pickersgill RW. Germin is a manganese containing homohexamer with oxalate oxidase and superoxide dismutase activities. Nat Struct Biol. 2000;7(11):1036-40.

101. Opaleye O, Rose RS, Whittaker MM, Woo EJ, Whittaker JW, Pickersgill RW. Structural and spectroscopic studies shed light on the mechanism of oxalate oxidase. J Biol Chem. 2006;281(10):6428-33.

102. Druka A, Kudrna D, Kannangara CG, von Wettstein D, Kleinhofs A. Physical and genetic mapping of barley (Hordeum vulgare) germin-like cDNAs. Proc Natl Acad Sci U S A. 2002;99(2):850-5.

103. Federico ML, Iniguez-Luy FL, Skadsen RW, Kaeppler HF. Spatial and temporal divergence of expression in duplicated barley germin-like protein-encoding genes. Genetics. 2006;174(1):179-90.

104. Zimmermann G, Baumlein H, Mock HP, Himmelbach A, Schweizer P. The multigene family encoding germin-like proteins of barley. Regulation and function in Basal host resistance. Plant Physiol. 2006;142(1):181-92.

\section{Submit your next manuscript to BioMed Central and we will help you at every step:}

- We accept pre-submission inquiries

- Our selector tool helps you to find the most relevant journal

- We provide round the clock customer support

- Convenient online submission

- Thorough peer review

- Inclusion in PubMed and all major indexing services

- Maximum visibility for your research

Submit your manuscript at www.biomedcentral.com/submit 